\title{
Struggling to be involved: An interprofessional approach to examine Māori whānau engagement with healthcare services
}

\author{
Dianne Wepa ${ }^{1 *}$, Denise Wilson²
}

\begin{abstract}
Wepa D, Wilson D. Struggling to be involved: An interprofessional approach to examine Māori whānau engagement with healthcare services. J Nur Res Prac. 2019; 3(3):01-05.
\end{abstract}

AIM: Explain the processes that whānau Māori used when engaging with healthcare services from an interprofessional approach.

METHODS: A qualitative design using kaupapa Māori methodology and constructivist grounded theory. The researchers were a registered social worker and registered nurse from New Zealand. We used semi-structured interviews with 20 Māori whānau (74 people aged 18-70 years) living in rural and urban areas in New Zealand about their engagement with healthcare services. The data analysis used constant comparative analysis to develop a substantive grounded theory to explain the processes Māori whānau use when engaging with healthcare services.

RESULTS: Māori whānau faced discrimination and constant struggles whilst engaging in health services to improve the health of their whānau member. Despite the many negative experiences, the collective orientation and the obligations of whānau contributed to their imperative to achieve the best healthcare for their whānau member. Struggling to be involved explains how Māori whānau experience and navigate healthcare services amid surviving the experience and being Māori, which together with a range of strategies that paradoxically assisted them to manage and survive their healthcare experience.

CONCLUSION: Current healthcare interventions do not appear to work for Māori whānau in our study. Struggling to be involved contributes new knowledge about nature of Māori whānau engagement with healthcare services and signals areas where interprofessionals can assist with reducing health inequities for Māori.

Keywords: Indigenous health; Maori; Whanau; Cultural safety; Constructivist grounded theory

\section{INTRODUCTION}

W hānau (extended family networks) are the fabric of Māori communities, whether these are whakapapa (genealogical) or kaupapa (shared purpose) whānau. The whānau exemplifies the collective orientation of Māori, whereby its members have responsibilities and obligations to others within its intergenerational network and to the whānau as a whole [1]. Whānau are a key source of whanaungatanga (connection), aroha (compassion), manaaki (caring) and tautoko (support), particularly in times of need such as when a member is unwell and requiring health care services [2]. At this time, whānau members are mobilised to provide the crucial support for one of their members with health care needs, and importantly to feel culturally safe.

Māori experience persistent inequities in health status and quality of health care compared to other groups of people living in Aotearoa [3]. These inequities are complex and multifaceted, primarily influenced by the disparities Māori have in access to the socio-economic determinants of health, differential access to health services and differences in quality of care [4-6]. Māori report struggling to have their cultural needs met when they engage with health services, particularly about the inclusion of their whānau and ensuring the wellbeing of their wairua (spirit). They also talk about differences in their interactions with health practitioners, including encountering discriminatory practices $[7,8]$. These factors are all quality of care factors that are amenable to change and could improve the experiences Māori have in their access to and engagement with quality health services [9].

There is a limited, albeit a growing, body of research about Māori health care experiences. Most literature focuses on barriers to accessing health care for Māori, related to higher levels of socio-economic deprivation and lower health status [10]. More recent literature highlights the role of racism Māori encounter, and its affects on their healthcare experiences and health outcomes [4,5]. Despite the importance of whānau in Māori health and wellbeing, little research exists about whānau perspectives of their engagement with healthcare services when supporting an unwell or ill whānau member. We report the findings from research with whānau about their interactions with health services.

\section{RESEARCH METHODOLOGY}

The research interface [11] enabled the use of kaupapa Māori methodology and Charmaz's constructivist grounded theory [12] to explore the cultural processes whānau Māori use when they engage with health care services. We incorporated tikanga Māori (protocols and processes) that included whakawhanaungatanga (the process of making connections), pepeha (introducing where the researcher is from), karakia (reciting a spiritual chant), and used of kai (food), pōwhiri (greeting and welcoming), and poroporoaki (closing) of the interviews $[13,14]$. Constructivist grounded theory provided a method to inductively analyse interviews. Developed by Kathy Charmaz [15], constructivist grounded theory enabled us to consider more than just looking at how whānau viewed their situations; it allowed the resulting theory to be co-created with the participants. Therefore, the interaction with whānau involved an interpretive process about how people create, enact, change meanings and actions. The coding of data for example, offered a conceptual interpretation rather than an exact portrayal of phenomena. Co-constructing data with whānau and recognising the subjectivity that influences their lives assisted with examining social processes surrounding the healthcare experience.

The research interface facilitated the generation of a Māori theoretical understanding of what happens for whānau Māori when they engage with healthcare services. We particularly focused on processes associated with whānau navigating their collective orientation and obligations within a healthcare system that focuses on individuals and their health problems.

\section{Data collection}

The Auckland University of Technology Ethics Committee (AUTEC $12 / 283$ ) approved the research. whānau were recruited through posters disseminated through iwi (tribal) liaison services. Seventy-four people in total were interviewed from 20 whānau who accessed hospital-based or primary healthcare in the previous 12 months. Five whānau lived rurally and fifteen

${ }^{1}$ School of Nursing and Midwifery, Division of Health Sciences, University of South Australia, Australia; ${ }^{2}$ Faculty of Health $\mathcal{E}$ Environmental Sciences, Auckland University of Technology, Private Bag 92 006, Auckland 1142, New Zealand

Correspondence: Dianne Wepa, School of Nursing and Midwifery, Division of Health Sciences, University of South Australia, C6-44, Centenary Building, City East Campus, Adelaide 5000, Internal Post Code CEA-17, Australia, Tel: +61 88302 2354; Fax: +61 88302 2118; e-mail: Dianne.Wepa@unisa.edu.au

Received: November 19, 2019, Accepted: December 16, 2019, Published: December 23, 2019 
lived in urban areas. The median age was 40 years. The youngest was 18 years old and the oldest, 70 years. Half of the participants were men and half were women. Semi-structured group interviews took place for one and a half hours. Five key informants involved in Māori health policy were also interviewed as part of developing theoretical sensitivity. Participants were excluded if they only wanted to be interviewed on an individual basis. The rationale for whānau inclusion was because they were rich informants of the patient's experience and the patient may not have recounted their experience accurately because of their health status at the time. Whānau also provided an added dimension to the healthcare experience as opposed to relying on one data source, such as an individual [8].

Interviews were audio-recorded, transcribed (by an independent transcriber) and checked for accuracy with identifying features removed. Simultaneously transcripts underwent constant comparative analysis to generate initial then focused codes and memos, with emerging categories and sub-categories refined and verified by theoretical sampling. These categories and subcategories were finalised once data saturation was reached [12]

\section{Theoretical sampling}

Purposive sampling occurred at the beginning of the study as whānau had knowledge of the phenomenon being studied. As the theory began to emerge, theoretical sampling then included other data. The goal was not to capture all possible variations of the topic being studied, but to gain a deeper explanation of the emerging analysis and facilitate the development of analytic frames and concepts [16]. Theoretical sampling can be viewed as a technique of data triangulation: using independent pieces of information to get a better fix on something that is only partially known or understood [17]. We theoretically sampled 'being Māori' by investigating literature and continuing with the constant comparison process. Having a constructivist assumption meant that we continued immersed in the study as social actors. Just like the research process itself which is an emergent social construction, we were never neutral or without context.

\section{Constructivist grounded theory}

The constructivist interview drew on whānau definitions of terms, situations and events, and uncovered assumptions and tacit meanings. The interviews contrasted with a traditional qualitative approach which is concerned with gathering information about the chronology of events and behaviours [12]. Asking 'tell me about, how, what, and when' assisted with interpretive enquiry and co-constructing the data. Engaging in active listening involved attending to the participants' language with research questions grounded in that emergent language. Questions such as 'could you describe ... further?' helped examine statements such as 'you know'. The use of 'you know' is a common verbal filler when a participant is struggling to articulate an experience and may want the interviewers' concurrence on the topic being discussed [15]. As the whānau and researchers shared a common heritage as Māori, the use of 'you know' was a tacit form of communication where the whānau thought we could relate to their situation as Māori. Ezzy [18] noted that emotional orientations of both the researcher and participant, inevitably influence the research process and should be engaged with. Including Charmaz and Ezzy's recommendations assisted with the co-construction of data and provided a 'third voice' of collaboration between us all [19].

\section{Kaupapa Māori practice}

Kaupapa Māori practices informed the process of undertaking the research, particularly about consultation, data collection, and dissemination of findings. We were cognisant as Māori researchers, we needed to ensure the research process was culturally safe for all participants [20]. We were mindful that the relationship between us all would endure beyond the study as we are part of the participants' community. With advice from our kaumatua (elders) regarding appropriate protocols, we engaged in whakawhanaungatanga (sharing our tribal connections). Allowing for time and space is critical to establish relationships with Māori participants [21]. The process of manaakitanga (nurturing and looking after people respectfully) involved conducting interviews at a place and time that was comfortable for the whānau. Interviews began with a karakia (prayer) followed by sharing of kai (food) and ending with a poroporoaki (farewell) [22].

\section{Data analysis}

The language of constructivist grounded theory focuses on meanings as concepts and categories. In contrast the language of other types of qualitative analysis, such as thematic analysis which focus on themes based on the researcher's interpretation of the data. Within this study, the approach involved data generation and analysis occurring simultaneously. The process began with memo writing, which occurred constantly and contributed to conceptualisation of emerging concepts and categories. Initial or open coding was the first step to analyse the data. We used the technique of gerunds (verbs used as nouns that always finish with 'ing') when coding as a way to identify processes in the data, as well as focusing on the whānau experience as a source of conceptual analysis [23]. Examples of using gerunds included 'having a bad day' and 'going to get better'.

Initial coding involved asking two key questions: 'what is the chief concern of the whānau?' and 'how do they resolve this concern? Table 1 provides an example of how we engaged initial coding where the participant describes a chronic health condition impacting on whānau activities. We used Strauss and Corbin's [24] components of a property to help unpack what was conveyed, namely frequency, degree and type. For example, the 'frequency' of the health condition impacted on whānau activities. The 'degree' of withdrawal from whānau activities, and the 'type' of activities that would be comfortable or not for her, due to level of pain. The initial codes of 'being debilitated, impacting on cultural and spiritual wellbeing, and withdrawing from whānau activities' were in vivo codes arising from the participant's own words. The basic social process for this whānau member was 'living with a chronic condition' and the consequence was 'withdrawing from whānau activities' which 'impacted on cultural and spiritual wellbeing'.

\section{TABLE 1}

Initial coding of transcript

\begin{tabular}{|c|c|c|}
\hline Transcript & Properties & Initial Coding \\
\hline $\begin{array}{l}\text { Yeah, definitely, there's a } \\
\text { definite link, }\end{array}$ & $\begin{array}{l}\text { Reduction in } \\
\text { participation } \\
\text { (frequency) }\end{array}$ & $\begin{array}{l}\text { Externalising } \\
\text { condition }\end{array}$ \\
\hline $\begin{array}{l}\text { You're debilitated } \\
\text { culturally and spiritually. }\end{array}$ & $\begin{array}{l}\text { Wanting to fully } \\
\text { participate (degree) }\end{array}$ & Being debilitated \\
\hline $\begin{array}{l}\text { I said, you're that } \\
\text { debilitated that you }\end{array}$ & $\begin{array}{l}\text { Assessing level of } \\
\text { pain (type) }\end{array}$ & Moving away from \\
\hline $\begin{array}{l}\text { actually can't contribute. } \\
\text { It has impacted }\end{array}$ & & $\begin{array}{l}\text { participating less } \\
\text { culturally }\end{array}$ \\
\hline $\begin{array}{l}\text { as it won't be that } \\
\text { comfortable. }\end{array}$ & & $\begin{array}{l}\text { holding back, } \\
\text { withdrawing }\end{array}$ \\
\hline
\end{tabular}

Focused coding followed where data was analysed further and involved constant comparison of data, categories and sub-categories. Exploration of relational statements contained in memos was an important aid during data analysis. Refining categories helped identify any gaps in the data and theoretical sampling progressed the stages of analysis, until theoretical saturation was achieved while considering the following processes:

\section{Breaking up the data into component parts or properties}

2. Defining the actions on which they rest

3. Looking for tacit assumptions

4. Explicating implicit actions and meanings

5. Comparing data with data, and,

6. Identifying gaps in the data [12].

\section{Constant comparative analysis}

Developed by Glaser and Strauss [16], constant comparative methods make assessments at each level of the research, where data is continually compared with the goal of finding similarities and differences. This type of analysis uses an inductive process, where analytical ideas emerge moving from comparing data with data, codes with categories and categories with concepts. Our analysis commenced early in the research. Careful coding assisted the analysis before we started to prevent our own 'pet' assumptions and attitudes becoming imbued in the data [16]. Field notes were recorded immediately after each interview in addition to transcribed recordings so that we could distinguish raw data from analytical abstractions. An example of an early field note Table 2 demonstrates participants sharing information on how negative the experience was for them while engaging with healthcare services. 
TABLE 2

Field note 03/04/2013

Topic Response

Many negative experiences emerging so far. Remember to code Negative for processes, actions and meanings and not topics and themes. experience for Under what conditions are the negative experiences occurring?

whānau How are whānau managing this situation and what are the consequences of how they manage the process of engagement?

\section{Analytic memos}

Analytic memos captured and tracked conceptual ideas and documented our thoughts about the emerging theory. Memos are not intended to describe the social worlds of the researcher's data, instead they conceptualise the data into a narrative. Memos are the analytical locations where researchers are most fully present and provided an audit trail to refine our theoretical sensitivity towards conceptualising the emerging codes and categories. Rather than providing an almost verbatim portrayal of peoples' narratives, we stressed identifying patterns of behaviour or actions taken by the whānau. The actions, events and stories were then fragmented to assist with theory development and then integrated to illustrate an analytic point rather than a complete narrative [12]. Table 3 provides an example of the rendering process where we became present and contributed to the narrative space between ourselves, the whānau and the reader.

TABLE 3

Analytic memo 10/1/2014

Topic Response

What are the conditions that haven't been considered? As a category, having a bad experience portrays whānau wanting the right care for their loved one despite the many negative experiences during this process. Becoming sensitised to potential patterns in the data has led to this question: is it the behaviour of the Having a bad health workers that needs further examination 'together' with experience relationships with whānau?

\section{RESULTS}

Struggling to be Involved explains the difficulties whānau Māori experience when engaging with healthcare services (Figure 1). To remain involved they draw on their collective identity, obligations to each other, and the responsibilities each member has to others and the whānau to overcome their concerns and needs. Nonetheless, they struggled to be involved for the betterment of their unwell whānau member, which compromised their physical and spiritual wellbeing and sapped their energy. Not knowing the rules of engagement contributed to having bad experiences and made getting the right care difficult. Previous health care experiences and whānau confidence to navigate a health care service influenced getting the right care. They encountered a lack of or wrong information, racism and being unable to 'connect' with healthcare practitioners all making getting the right care challenging.

We didn't know what we didn't know. We fumbled along as we went. We wish we were told earlier, it would have saved a lot of time and energy.

No one tells you what's going to happen. It's like there are these unwritten rules that you have to guess. They [health practitioners] know the rules because they are in it every day. Just doesn't seem right.

Having a bad experience included factors such as healthcare practitioners lacking empathy and compassion, the scheduling of multiple appointments for various people on different days, health service and personal complexities, and feeling devalued. However, whānau believed by enduring these challenges they eventually got the right care.

I didn't want to rock the boat. I was afraid to ask anything in case they were going to ignore me.

When entering a health care service, whānau assumed they would receive information, but this was frequently not the situation - instead frustrated, whānau felt compelled to ask questions without knowing what they should be asking. Whānau felt silenced and further frustrated by being unable to ask questions and receive answers to questions.

Expectation is the mother of all frustration. After going to 20 appointments with no answers to my questions, I had lots of frustration to go around.

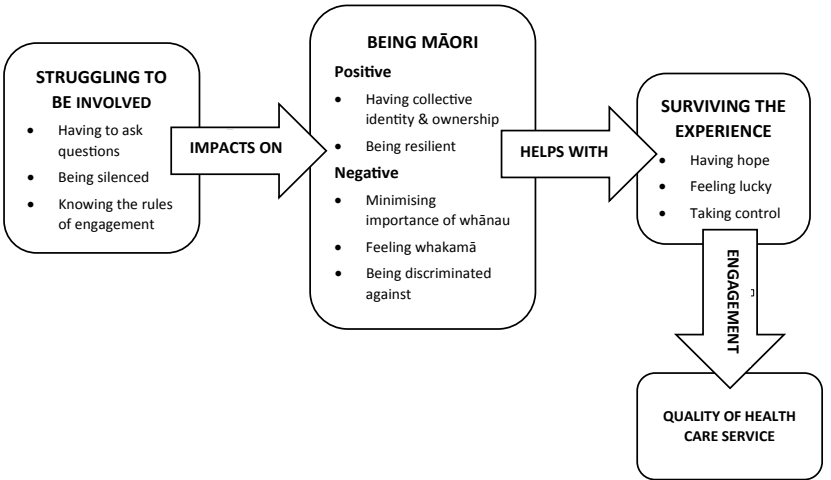

Figure 1: Struggling to be Involved ${ }^{1}$

Being Māori reflected a collective orientation, and significant social component of Māori personal health journeys. Participants linked an individual's healthcare encounters with the collective whānau experience of that person receiving healthcare, evident in phrases such as "as Māori", "as whānau" and "we." The following terms captured their collective identity:

We don't do anything on our own

We are just worrying about whānau being cared for.

We all do that - making sure someone's checking up on them.

This collective identity aided participants' resolve to endure their healthcare journey because of their obligations and crucial importance in the healthcare experience of those who are unwell. They survived by having hope, feeling lucky and taking control of their healthcare journey. Whānau resilience, aided by the collective endeavour of remaining involved and obtaining the right health care, helped endure having a bad experience. However, negative aspects such as the devaluing of the importance of whānau, feeling whakamā (embarrassed or shy) especially when having to continually ask questions, and encountering discrimination and racism, countered the positive aspects of being Māori.

Aunty fell out of the wheelchair. I rang the nurse to check on her. Aunty said, "I'm alright." But, she wasn't. They're too whakamā (embarrassed) or they don't want to put the doctor out.

We felt that if she was a white male having a heart attack, she would have been sent to Auckland straight away for surgery. That's what happened to my boss. But, instead she was told to go on medication for the rest of her life.

We just felt stink, the way we were treated. It was shameful how we were growled at when we turned up. Yes, we were late, but at least we were there!

Being unheard or not understood, impacted whānau receiving and comprehending the right information in culturally relevant and meaningful ways. In addition to feeling whakamā, whānau perceived providers of health care devalued them.

It felt like this big gap between myself and the nurse. Knowing someone takes a bit of effort. It was like she didn't want to try to get to know me and understand why my whānau wanted to have karakia [prayers] with me each evening. That made me very sad. I just wanted to get out of there [the hospital] as soon as I could.

The patient's whānau is a willing resource who, for instance, can assist the patient understanding information they receive rather than being a hindrance-something they interpreted they were. The actions of whānau and their resilience in the face of challenging situations, draws on the collective skills that exist within the whānau so the person requiring health care and the whānau can cope with the unfolding events (positive or negative), including assisting with decision-making.

Being Māori and the integral support provided by the collective whānau paradoxically assists surviving healthcare experiences, although oftentimes it is in the face of unnecessary challenges to do so. While being Māori helps with surviving the health care experience, and even when confronted by negative people and situations, having hope, feeling lucky and taking control aided whānau to survive. Having hope helped whānau believe that the outcomes would be positive, and for instance, treatment successful.

${ }^{1}$ Wepa, D. (2016) Struggling to be Involved: A grounded theory of Māori whānau engagement with healthcare. (unpublished doctoral thesis) Auckland University of Technology, Auckland, New Zealand 
We put a lot of emotional and spiritual energy into going through all that treatment. We know there is not a magic bullet, just hope.

Whānau also hoped that healthcare practitioners would be empathetic and value the role that they had in the support of a whānau member.

We hoped that by telling our story about our concerns then there would be someone to hear us - truly hear us. A place that doesn't hear our stories is a place that doesn't allow us to hope.

While feeling lucky was associated with being resourceful and thankful, it was also about the whānau connections to their community and the source of support and strength this provided. Community, just like whānau, was an important coping strategy. Whānau endeavoured to take control and manage their collective health and wellbeing, driven by their optimism and amid the hostility and foreign nature of healthcare service environments. In the process, they attempted to make healthcare practitioners "care" with the aim to help them understand and to listen to information. The aim of whānau and their activities is towards engaging with the health care service and receiving quality of care.

\section{DISCUSSION}

This research demonstrates the importance of whānau Māori in the healthcare journey of Māori. It is commonly understood that whānau provide a vital part of a patients' healthcare journey, hence the importance of understanding Whānau perspectives and experiences of engaging with health services. While the predominant ideology driving the New Zealand health system is on individuals and their healthcare, this is generally at the exclusion, to some degree, of their whānau. A key finding of this research is the prevalent focus on "we" (the collective) rather than "I" (the individual) for both the Māori seeking healthcare and their whānau.

Health is a socio-cultural construction shaped by the worldview people hold, which in turn influences what they perceive as important for their health and wellbeing. The worldview of the New Zealand health system is predominately a western biomedical approach that for the most part focuses on individuals and their health experiences. This contrasts with Māori worldviews, similar to other Indigenous peoples, that are more holistic, spiritual and relational in nature, underpinned by whakapapa and the values and tikanga of Māori culture $[25,26]$. Therefore, Māori focus on the collective whereby the integral connection whānau members have to one another underpins their responsibilities and obligations to each other and the collective. Penetito [27] affirms this, saying:

Māori like to do things together, to acclaim their Māoriness to one another, to meet and strengthen their social bonds for each other, to participate in games that challenge and unite, to share food, stories, and histories, and to remember those no longer in the world of the light.

Culturally appropriate health services are contingent on the inclusion of a patient's cultural beliefs and practices in their plans of care [28,29]. In this study however, healthcare practitioners talked about whānau involvement but lacked knowledge about how to engage and then mobilise whānau in a practical way that could be sustained to improve their member's health and wellbeing. The presence of whānau during consultations was an uncomfortable experience for the health practitioners. Despite Māori consenting to their whānau being involved in some way with their treatment, the reluctance demonstrated by the health practitioner was overwhelming.

We found whānau presence during Māori healthcare experiences alleviated any emotional and spiritual fatigue associated with trying to survive their experience and navigate the complexities of health services they encountered. Spiritually, whānau provided a culturally safe space to be and function as Māori. The complexity for individuals navigating through health services is minimised with the inclusion of whānau support strategies. Pragmatically, whānau use their collective identity and obligations to assist in activities such as travel to appointments. Everyone's personal wellbeing and identity was closely connected to the health and wellbeing of the collective [30,31].

Despite the paradox associated with being Māori, any tension arising did not prevent whānau seeking and achieving an outcome of some sort during their whānau member's healthcare engagement. In reality, being Māori helped with surviving their experiences during healthcare engagement. Accepting whānau collectively as key partners in the healthcare journey of Māori requires active participation by the health practitioners. Pre-registration health and medical programmes provide a focus on meeting the cultural safety and cultural responsiveness requirements of Māori [32]. However, a dis-connect remains between the theory and practice of positively engaging Māori whānau during their healthcare journey.

\section{CONCLUSION}

Current healthcare interventions do not appear to work for Māori whānau in our study. Struggling to be involved contributes new knowledge about nature of Māori whānau engagement with healthcare services and signals areas where interprofessionals can assist with reducing health inequities for Māori.

\section{REFERENCES}

1. Metge J. New growth from old: The whānau in the modern world. Wellington, Victoria University Press, New Zealand. 1995.

2. Mead MH. Tikanga Māori :Living by Māori values. Wellington, New Zealand: Huia. 2003.

3. Ministry of Health. Tatau Kahukura Māori health chart book 2015 (3rd ed). Wellington, New Zealand: Ministry of Health. 2015.

4. Cormack, D, Stanley J, Harris R. Multiple forms of discrimination and relationships with health and wellbeing: findings from national cross-sectional surveys in Aotearoa/New Zealand. Int J Equity Heal. 2018; 17:p26.

5. Harris R, Cormack D, Tobias M, et al. Self-Reported experience of racial discrimination and health care use in New Zealand: Results from the 2006/07 New Zealand Health Survey. American J Public Heal. 2012;102(5): 1012-1019.

6. Smith RJ, Sarfati D, Hider P, et al. Ethnic disparities in the quality of hospital care in New Zealand, as measured by 30-day rate of unplanned readmission/death. Int J Qual Heal Care. 2013;25(3): 248-254.

7. Walker T, Signal L, Russell M, et al. The road we travel: Māori experience of cancer. New Zealand Med J. 2008;121(1279).

8. Wilson D, Barton P. Indigenous hospital experiences: A New Zealand case study. J Cli Nur. 2012;21: 15-16.

9. Ministry of Health. Annual update of key results 2015/16: New Zealand Health Survey. In. 2016.

10. Marriott L, Sim D. Indicators of inequality for Māori and Pacific people. J New Zealand Studies. 2015.

11. Durie M. Understanding health and illness: Research at the interface between science and indigenous knowledge. Int J Epidemiol. 2004;33(5).

12. Charmaz K. Constructing grounded theory (2nd ed). Los Angeles: Sage. 2014.

13. Pihama L. Kaupapa Māori theory: Transforming theory in Aotearoa. He Pukenga Korero. 2012;9.

14. Rewi T. Utilising kaupapa Māori approaches to initiate research. MAI J. 2014;3(3): 242-254.

15. Charmaz K. Grounded theory. Objectivist and constructivist methods. In N. Denzin \& Y. Lincoln (Eds.), Handbook in qualitative research ( $2^{\text {nd }}$ ed) Thousand Oaks, CA: Sage. 2000.

16. Glaser B, Strauss FA. The discovery of grounded theory. Chicago: Aldine. 1967.

17. Denscombe M. The good research guide for small-scale social research projects ( $3^{\text {rd }}$ ed): McGraw Hill, USA. 2007.

18. Ezzy D. Qualitative interviewing as an embodied emotional performance. Qualitative Inquiry. 2010;16(3): 163-170.

19. Atkinson P, Coffey A, Delamont S. Key themes in qualitative research Continuities and changes. New York: Rowan and Littlefield. 2003.

20. Kearns R, Dyck I. Culturally safe research. In D. Wepa (Ed.), Cultural safety in Aotearoa New Zealand, Auckland, New Zealand: Pearson. 2005 79-88.

21. Edwards S, McCreanor T, McManus V. Collaborative research with Māori on sensitive issues: the application of tikanga and kaupapa in research on Māori sudden infant death syndrome. Social Policy J New Zealand. 2005;25:88-104.

22. Bridgman G, Dyall L. A Framework for Examining Mental Health Outcomes. Paper presented at the Mental Health Services Eighth Annual Mental Health Service Conference, Hobart, Australia. 1998. 
23. Birks M, Mills J. Grounded theory: A practical guide. London, England: Penguin. 2011.

24. Strauss A, Corbin J. The basics of qualitative analysis: Grounded theory procedures and techniques. Newbury Park CA: Sage. 1990.

25. Mead HM. Tikanga Māori: Living by Māori values (Revised ed.). Wellington, New Zealand: Huia. 2016.

26. Royal TAC. The woven universe: Selected writings of Rev. Māori Marsden. Ōtaki, New Zealand: Te Wānanga-o-Raukawa. 2003.

27. Penetito WT. A sociology of Māori education: Beyond mediating structures. (Doctor of Philosophy), Victorial University of Wellington, Wellington, New Zealand. 2005.
28. Webb R, Shaw RM. Whanau, whakapapa and identity in experiences of organ donation and transplantation. Sites: A Journal of Social Anthropology and Cultural Studies. 2011;8(1).

29. Wilson D. The significance of a culturally appropriate health service for Indigenous Maori women. Contemp Nurse. 2008;28: 173-188.

30. Lyford S, Cook P. The Whanaungatanga model of care. Nursing Praxis in New Zealand. 2005;21(2): 26-36.

31. Pitama S, Robertson P, Cram F, et al. Meihana model: A clinical assessment framework. New Zealand J Psy. 2007;36(3): 118-125.

32. Wepa D. Cultural safety in Aotearoa New Zealand ( $2^{\text {nd }}$ ed) Cambridge University Press, Melbourne, Australia. 2015. 